\title{
Simultaneous visual adaptation to tilt and displacement: A test of independent processes*
}

\author{
GORDON M. REDDING $\dot{\dagger}$ \\ University of Wisconson. Madison. W'is. 53706
}

Change in both visual direction and visual orientation was assessed following simultaneous exposure to both optical displacement and optical tilt. Tilt adaptation when both transforms were present was not different from tilt adaptation when Ss were exposed to optical tilt alone. A slight decrease in displacement adaptation when the transforms were presented simultaneously was found to be attributable to oblique displacement of the straight-ahead point produced when the optic array is first displaced and then rotated. It was concluded that adaptation to both transforms simultaneously is not different from adaptation to each transform separately, consistent with the view that the two kinds of adaptation involve independent visual systems.

Adaptation to optical tilt and optical displacement of the visual field have been variously explained as involving a change in point localization (Mikaelian \& Held, 1964; Held, 1968), or a recalibration of the retinal-cortical egocentric coordinate system (Rock, 1966 , pp. 33.34, 141-144), or a change in registered eye position (Ebenholtz, 1970; Harris, 1965, 1966). These theories have in common the attempt to explain both kinds of adaptation within the framework of a single unitary process. However, there have been few attempts to compare the transforms experimentally (e.g., Mikaelian \& Held, 1964), and conclusions regarding general process are unjustified.

The research reported here was undertaken to test whether tilt and displacement involve a common perceptual system. The procedure required that Ss be simultaneously exposed to lateral displacement and tilt of the visual field. Three levels of tilt and three levels of displacement, including the zero level of each transform, were factorially combined in a completely randomized design. Change after exposure in both visual direction and visual orientation was assessed. The rationale of this procedure was that combination of tilt and displacement produces a more difficult problem of compensation if adaptation to the two transforms has the same locus. One could reasonably expect interference, evidenced by reduced adaptation to the simultaneous transforms, if a single system is involved.

\section{METHOD \\ Procedure}

Ss walked through a hallway while viewing an optically

*This paper is based on a dissertation submitted to the University of Wisconsin, Madison. The author is grateful for the advice and encouragement of Sheldon $M$. Ebenholtz, who sponsors this paper and takes full editorial responsibility for it William Epstein, and Dominic W. Massaro, and for the helpful comments of fellow graduate students.

tRequests for reprints should be sent to Gordon M. Redding, now at Illinois State University, Normal, Ill. 61761. transformed visual field with the right eye, the left eye being occluded. Tilt was produced by a pair of dove prisms mounted in tandem and affixed by a headset over the right eye. Displacement was produced by wedge prisms mounted in front of the dove prisms (relative to the S). Horizontal orientation of the wedge prism was maintained, regardless of the degree of tilt. For zero displacement, a glass flat was used in place of the wedge prism. Exposure time was $15 \mathrm{~min}$, and only the exposed (right) eye was tested.

Prior to the start of the adaptation period, baseline measures of apparent vertical and apparent straight-ahead were obtained. Each $\mathrm{S}$ was tested on visual orientation by setting a luminous line $(30.48 \mathrm{~cm}$ long, $.32 \mathrm{~cm}$ wide), viewed in the frontal plane at a distance of $137.16 \mathrm{~cm}$, with the bottom and pivot point at eye level and on line with the nose, to look lined up with his chin-forehead axis. Each $\mathrm{S}$ was tested on visual direction by setting a vertical row $(.79 \mathrm{~cm}$ long, $.16 \mathrm{~cm}$ wide) of three illuminated dots, viewed in the frontal plane at a distance of $121.92 \mathrm{~cm}$, with the center dot at eye level and on line with the nose, to look straight ahead of his nose in the horizontal plane. Each test required two judgments, once from each of two starting positions, $25 \mathrm{deg} \mathrm{CW}$ and $25 \mathrm{deg} \mathrm{CCW}$ for the line and $8 \mathrm{deg}$ right and $8 \mathrm{deg}$ left for the dots. Level of adaptation (LA) was defined as the difference between the mean of the two preadaptation measures and the mean obtained on posttests. All testing was conducted without prisms.

\section{Design}

Seventy-two undergraduates (48 female and 24 male) were run in nine groups of $8 \mathrm{Ss}$ each, with random assignment to groups. Twenty-two Ss were eliminated when they showed an error of more than $1 \mathrm{deg}$ from objective vertical on the pretest. Eleven Ss were eliminated when they showed an error of more than $2 \mathrm{deg}$ from objective straight-ahead on the pretest. Fourteen other Ss failed to show acceptable accuracy on both pretests. As a $\mathrm{S}$ failed to meet criterion, he was immediately replaced by the next available $S$, such that random assignment was maintained. The nine groups were generated by the factorial combination of three levels of rightward displacement $(0,10$, $20 \mathrm{D})$ and three levels of $\mathrm{CW}$ tilt $(0,10,20 \mathrm{deg})$. Order of testing (orientation first or direction first) and order of starting position of the test apparatus were counterbalanced within groups.

\section{RESULTS AND DISCUSSION}

Results are presented in Fig. 1. Adaptation to displacement and to tilt are shown on the left and right, respectively. The lines are the best linear fit by eye, and represent the effects of tilt and displacement on displacement and tilt adaptation, respectively. Displacement had no effect on tilt adaptation, $F(2,63)=.63$. The only significant source of variance in tilt adaptation was optical tilt, $F(2,63)=49.57$, $\mathrm{p}<.001$. Optical displacement was a significant factor in displacement adaptation, $F(2,63)=6.39, \mathrm{p}<.005$. Despite appearances in displacement adaptation, the interaction of Tilt by Displacement was not significant, $F(4,63)=1.09$. A main effect of tilt was found, $F(2,63)=3.29, p<.05$, but only the reduction in displacement adaptation from 0 to $20 \mathrm{deg}$ was significant, $F(1,63)=6.20, \quad p<.025$. Displacement adaptation at $10 \mathrm{deg}$ of tilt was not significantly 


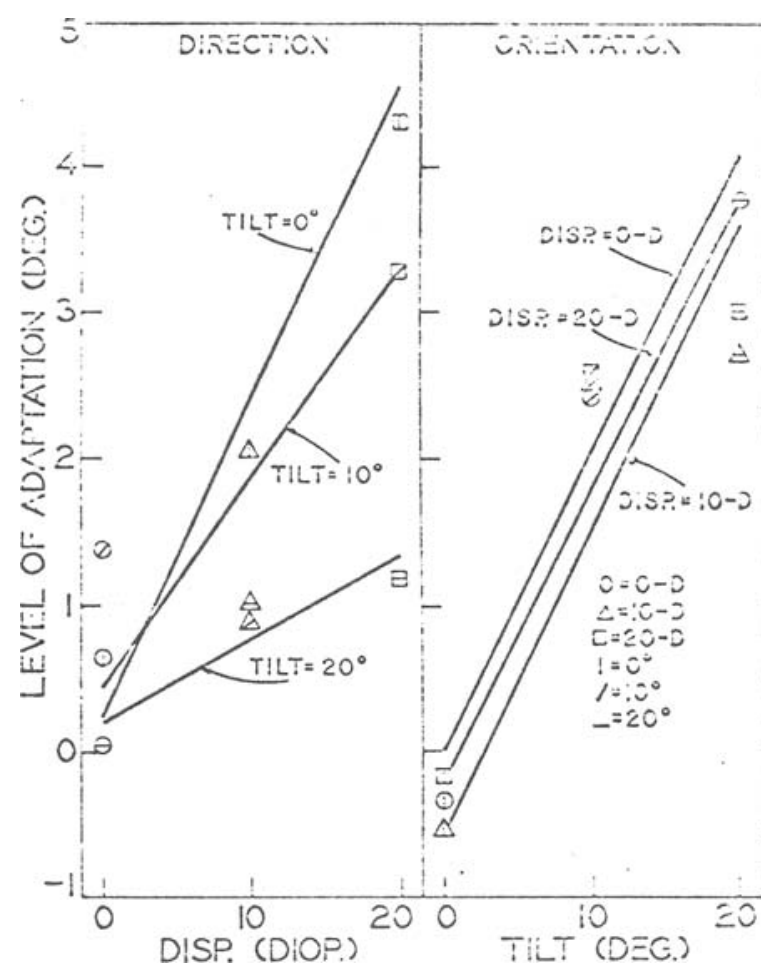

Fig. 1. Mean change (level of adaptation) in visual direction and visual orientation as a function of combined levels of optical tilt and displacement. (The lines are the best linear fit by eye.)

different from that at 0 deg of tilt, $F(1,63)=.51$.

The effect of tilt on displacement adaptation suggests an interaction of tilt and displacement in determining direction. Such a relationship is not unreasonable (e.g., see Rock, 1966, pp. 141-144), but the effect of tilt is unconvincingly small relative to error variance. Examination of the procedure used to combine tilt and displacement suggested an alternative explanation.

Since the wedge prism was placed in front of the dove prisms (relative to the $\mathrm{S}$ ), the order of combination of the two transforms was first displacement and then tilt. The objective center of the optic array was first displaced by the wedge prism. Then tilt rotation was performed about the optical center. The consequence of such a combination is oblique displacement of the straight-ahead point along an axis rotated 10 or $20 \mathrm{deg}$. The reduction in displacement adaptation with increasing tilt might be due to the change from lateral to increasingly oblique displacement. Hay \& Pick (1966) found eye-hand compensation for 20-D vertical displacement to be only about $60 \%$ that for horizontal displacement after $12 \mathrm{~h}$ of exposure. It is, therefore, reasonable to expect that the horizontal component of adaptation to displacement along axes rotated less than $90 \mathrm{deg}$ will be less than that to lateral displacement.

To evaluate this hypothesis, three additional groups of eight Ss each were tested. Groups 1 and 2, respectively, replicated the 0-deg/20-D and 20-deg/20-D conditions of the first experiment. A third group received 20-D displacement and no tilt: however, the displacement was along an oblique axis, produced by a 20-deg CW rotation of the wedge prism. If the effect of tilt on displacement adaptation were due to oblique displacement, Group 2 and 3 should not be different from each other, but both should show less displacement adaptation than Group 1 .

This was, in fact, the outcome. The mean LA to displacement was $3.81,1.53$, and 1.84 , respectively, for Groups 1, 2, and 3. Planned comparisons revealed no difference in adaptation between Groups 2 and 3, $t(21)=.28$, but the average adaptation in Groups 2 and 3 was significantly less than in Group $1, \mathrm{t}(21)=2.22$, $\mathrm{p}<.025$. The mean LA to tilt was $.06,2.66$, and -.41 , respectively, for Groups 1, 2, and 3. No difference occurred between Groups 1 and $3, \mathrm{t}(21)=1.11$, but Group 2 showed greater tilt adaptation than the average of Groups 1 and 3, $\mathrm{t}(21)=6.60, \mathrm{p}<.01$.

The horizontal component of adaptation to oblique displacement is less than that to horizontal displacement. The reduction in displacement adaptation found with increasing tilt is due, therefore, to the change from lateral to increasingly oblique displacement. Optical tilt and optical displacement affect different and independent visual systems. This conclusion is consistent with an increasing body of data that indicates a dissociation between neural mechanisms mediating location and relational perception (Bishop \& Henry, 1971; Held, 1970, 1968; Schneider, 1969). These findings suggest that displacement adaptation should be identified with the locus-specific analysis of retinal stimulation necessary for the perception of location, and tilt adaptation with the relational analysis involved in form perception.

\section{REFERENCES}

Bishop, P. O., \& Henry, G. H. Spatial vision. In P. H. Mussen and M. R. Rosenzweig (Eds.), Annual review of psychology. Palo Alto, California: Annual Reviews, 1971.

Ebenholtz, S. M. On the relation between interocular transfer of adaptation and Hering's law of equal intervention. Psychological Review, 1970, 77, 343-347.

Harris, C. S. Perceptual adaptation to inverted, reversed, and displaced vision. Psychological Review, 1965, 72, 419-444.

Harris, C. S. Through the looking glass: Adapting to an optically reversed world. Symposium on Perceptual Change, American Association for the Advancement of Science, Washington, D.C., December 1966 .

Hay, J. C., \& Pick, H. L. Gaze-contingent prism adaptation: Optical and motor factors. Journal of Experimental Psychology, 1966, 72, 640-648.

Held, R. Dissociation of visual functions by deprivation and rearrangement. Psychologische Forschung, 1968, 31, 338-348.

Held, R. Two modes of processing spatially distributed visua stimulation. In The neurosciences, second study program. New York: Rockef eller University Press, 1970.

Mikaelian, H. H., \& Held, R. Two types of adaptation to an optically rotated visual field. American Journal of Psychology, 1964, 77. 257-263.

Rock, I. The nature of perceptual adaptation. New York: Basic Books, 1966.

Schneider, G. E. Two risual systems. Science, 1969, 163, 895-902.

(Received for publication A pril 26, 1973.) 